\title{
The Effects of Music Listening and Education on Reducing Pain from Total Joint Arthroplasty
}

\author{
Yi-Li Ko ${ }^{1}, \mathrm{Su}-\mathrm{Yu} \mathrm{Chang}^{2}$, Yu-Tai Lee ${ }^{2} \&$ Pi-Chu Lin ${ }^{3}$ \\ ${ }^{1}$ Department of Nursing, College of Medicine, Catholic Fu-Jen University, New Taipei City, Taiwan \\ ${ }^{2}$ Department of Nursing, Taipei Veterans General Hospital, Taiwan \\ ${ }^{3}$ College of Nursing, Taipei Medical University, Taipei, Taiwan \\ Correspondence: Pi-Chu Lin, EdD, RN, Professor, Master Program in Long-term Care and School of Nursing, \\ College of Nursing, Taipei Medical University, Taipei, Taiwan.
}

Received: November 23, 2016

Accepted: December 12, 2016 Online Published: December 18, 2016

doi:10.20849/ijsn.v1i1.98

URL: http://dx.doi.org/10.20849/ijsn.v1i1.98

\begin{abstract}
Aims: The purpose of this study was to evaluate the effects of pain education combined with music intervention on pain levels and the beliefs about and satisfaction with pain management.

Methods: This study was conducted using a quasi-experimental pretest-posttest design involving an experimental group and control group. The sample size was 60; each group consisted of 30 participants. The control group received routine care, whereas the participants in the experimental group received pain education and a music intervention program.

Results: No significant difference was observed in average pain levels between the two groups. Most patients in the experimental group considered the effects of music to be satisfactory in relieving pain. No difference was observed in beliefs about and satisfaction with pain management between the two groups.
\end{abstract}

Conclusions: The results can be used as a reference in clinical practice for joint replacement patients who require pain and anxiety management.

Keywords: postoperative pain, pain education, music listening, total joint arthroplasty

\section{Introduction}

Postoperative pain is a major concern for surgical patients. Orthopedic surgery is considered a particularly painful procedure (Lin et al., 2016). The severe pain experienced after orthopedic surgery is due to the demanding surgical procedure, which involves muscle and skeletal tissue repair or reconstruction (Pasero \& McCaffery, 2007). In addition, postoperative rehabilitation exercise must be performed (Parker, 2011). The medical profession has devoted considerable effort to managing pain by developing new approaches to relieving pain, including medication for pain relief, and establishing pain-management guidelines. However, adequate pain management remains an important issue for postoperative patients. Hill and Davis (2000) indicated that $60 \%$ of patients who had undergone total hip arthroplasty (THR) and total knee arthroplasty (TKR) experienced severe pain after surgery. Busch et al. (2006) estimated that postoperative pain following total knee arthroplasty was severe in $60 \%$ of patients and moderate in a further $30 \%$. Pain interfered most with walking (5.9), exercise (5.8), general activity (5.4), and sleep (4.0; on a scale of 0 to 10) (Akyol, Karayurt, \& Salmond, 2009). Parker (2011) indicated that postoperative measures for TKR surgery should focus on reducing pain and rehabilitation exercises to restore walking ability. However, patients are often hesitant to take a sufficient amount of analgesics to lower pain levels, and take fewer analgesics than instructed, even if they report high pain levels (Pellino et al., 2005). Elderly people in particular are convinced that they must endure pain, and thus, their pain levels are not usually fully documented (Brown, 2004; Vallerand, Foulabakhsh, \& Templin, 2005).

Non-pharmacologic measures may be effective in pain management, but are often overlooked or underused. Nurses familiar with simple and noninvasive non-pharmacologic measures, such as patient positioning, massage therapy, relaxation techniques, music listening, and cold applications, can identify and educate patients who may benefit from them (Gatlin, 2007; Lin, 2012; Lin, Lin, Huang, Hsu, \& Lin, 2011). In previous studies, pain education, music listening, and relaxation therapy were found to have positive effects on postoperative pain 
relief (Buyukyılmaz \& Ast1, 2013; Chen, Chen, \& Lin, 2014; Lin, 2012; Lin et al., 2011). However, non-pharmacological approaches supporting pain management have not been integrated into standard postoperative pain-management procedures, and thus, they are not applied to postoperative patients. Scholars have noted that music is often used with other activities such as education programs, videos, and massages (Evans, 2002). Regarding the current study, music and pain-control information were used as complementary measures of pain management. This study investigated how pain education and music listening affected postoperative pain.

\subsection{Aims}

The aims of this study was to evaluate the effects of pain education combined with music intervention on pain levels, and the beliefs and satisfaction with pain management of patients who had undergone hip or knee surgery.

We propose the following hypotheses:

1. Patients receiving pain education combined with music intervention experience lower pain levels than patients receiving routine care.

2. Patients receiving pain education combined with music intervention have more positive beliefs about pain management compared to patients receiving routine care.

3. Patients receiving pain education combined with music intervention have higher satisfaction levels of pain management compared to patients receiving routine care.

\section{Literature Review}

\subsection{Postoperative Pain}

Pain is a multilevel phenomenon that includes physiological responses, feelings, emotions, cognition, and behavior. Postoperative pain has a negative impact on patients, both physically and psychologically (Sagrillo \& Mooney, 2000). Physically, pain results in a systemic dysfunction, affecting the respiratory, cardiovascular, digestive, urinary, muscular, endocrinal, and metabolic systems (Giannoudis, Dinopoulos, Chalidis, \& Hall, 2006). Psychologically, pain makes patients uncomfortable and causes anxiety and fear, and also disrupts sleep and appetite (Brunges \& Avigne, 2003).

Postoperative pain is caused by ischemia and the release of neuropeptides at the site of the trauma and throughout the nervous system. Numerous studies continue to indicate problems with postoperative pain following orthopedic surgery (Akyol et al., 2009; Buyukyılmaz \& Ast1, 2010; Joelsson, Olsson, \& Jakobsson, 2010; Lin 2012; Stomberg \& Oman, 2006). Akyol et al. (2009) investigated 125 patients who had undergone total knee replacement surgery, and found that the highest pain levels that patients experienced during 3 days after surgery was $7.20 \pm 1.95$ (on a scale of 0 to 10). Buyukyılmaz and Ast1 (2010) investigated 150 patients who had undergone major orthopedic surgery. Patients verbalized their pain at the highest percentages as "throbbing," "tiring," "troublesome," and "nagging," and 78.7\% stated that position change and physical therapy (69.3\%) increased their pain. In the assessment of pain intensity on the third postoperative day, the most severe pain was determined to be a mean of $4.55 \pm 0.70$ (on a scale of 0 to 5). Stomberg and Oman (2006) surveyed 112 patients undergoing total hip arthroplasty. The worst pain experience was $47.8 \pm 28.7$ (VAS $100 \mathrm{~mm}$ ) on the fourth postoperative day. The pain experience for most patients was reported to be highest on the first postoperative day. In a study on 93 patients who had undergone total joint arthroplasty, Lin (2012) found that the highest pain level on the first day after surgery was 6.56 points (on a scale of 0 to 10 points). Joelsson et al. (2010) interviewed 15 total hip replacement patients, and found that the postoperative pain experience was characterized as interrelated contexts of time, various bodily activities, and postoperative pain intensity, and indicated that, although the development of THR surgery has been successful, postoperative pain management still requires further attention.

\subsection{Pain Education}

Pain education is an important medium for communicating self-care information about non-pharmacologic methods for managing postoperative pain (Tracy, 2010). Pain education can be applied alone or combined with medication, for which the side effects of medicines can usually be reduced. The purpose of pain education is to change patients' erroneous beliefs about pain, enhance their expectations of pain control, and achieve improved postoperative pain control through behavioral changes (Tracy, 2010). Effective pain education may improve patient satisfaction with pain management (Tracy, 2010; Tracy et al., 2006).

Chen et al. (2014) provided the experimental group with a cognitive-behavioral education on performing TKR rehabilitation treatment and pain management plans. The results showed that the experimental group had lower 
levels of postoperative pain than the control group. Wong, Chan, and Chair (2010) designed a 30-min preoperative educational intervention for patients with fractured limbs. The result showed that the experimental group had a significantly lower pain barrier and experienced lower pain levels. Pellino et al. (2005) reported that total joint replacement patients who received pain-kit education tended to use fewer opioids than patients who had not received the kit. Tracy (2010) designed a seven-step tailored teaching intervention (TTI) for older joint replacement patients within the context of a translational research model that included the following steps: (a) assessing the patient's information-coping style; (b) assessing the patient's prior use of non-pharmacologic methods; (c) providing and reviewing a pamphlet containing information on music, self-guided imagery, and slow-stroke massage; (d) viewing of a videotape explaining teaching information; (e) the development of a personalized pain management plan; (f) daily follow-up; and (g) revision of the pain management plan, as required. The results showed that TTI could significantly change subjects' knowledge of and attitudes toward non-pharmacologic methods for pain management, increase their satisfaction levels with the non-pharmacologic methods they chose, and enhance their use of non-pharmacologic methods during the hospital stay.

\subsection{Music Intervention}

Music listening is a noninvasive, economical, and safe nursing intervention that has been successfully used in hospitals (McCaffrey \& Locsin, 2006). The common theory regarding the pain-reducing effect of music is that music is a distraction, diverting the patient's attention from negative stimuli toward something pleasant and encouraging. Music occupies the patient's mind with something familiar and soothing, which allows the patient to escape into his or her own world (Nilsson, 2008).

Several studies have shown that music reduced postoperative pain levels (Joanna Briggs Institute, 2009; Lin et al., 2011; Lukas, 2004; Sendelbach, Halm, Doran, Miller, \& Gaillard, 2006), whereas two other studies have shown that music reduced opioid intake after surgery (Cepeda, Carr, Lau, \& Alvarez, 2006; Joanna Briggs Institute, 2009). Lukas (2004) investigated 31 orthopedic outpatients who listened to music preoperatively, intraoperatively, and postoperatively. The results indicated that participants overwhelmingly felt that music listening was a positive addition to traditional pain and anxiety management techniques. In a study by Lin et al. (2011), 60 spinal surgery patients listened to music of their choice for $30 \mathrm{~min}$ at 7:00 PM the day before surgery, $1 \mathrm{hr}$ before surgery, and at 3:00 PM on the first and second days after surgery. The differences between the 2 groups in the visual analog scale (VAS) pain score and mean blood pressure $1 \mathrm{hr}$ after surgery were statistically significant, but no significant differences were found between the 2 groups in urine cortisol, norepinephrine, or epinephrine values.

However, two studies have reported no effect of music on reducing opioid usage by patients who had undergone cardiac surgery, or on the dosage of sedative medications for patients who had undergone a colonoscopy or cardiac surgery (Bechtold et al., 2009; Sendelbach et al., 2006). Engwall and Duppils (2009) conducted a meta-analysis of 18 studies on the effect of music on postoperative pain. The results of 15 of these studies have indicated a significant positive effect of music on postoperative pain. Four of the studies found that the use of analgesics was lower for intervention groups. The results of the literature review show that the effects of music listening on pain reduction in patients recovering from surgery are vary.

\section{Methods}

This study was conducted using a quasi-experimental pretest-posttest design involving an experimental group and a control group. All subjects were sequentially recruited into the experimental or the control group. To prevent interactions between patients in the 2 groups, patients in the control group were enrolled first. After completing enrollment of the control group, we started enrolling for the experimental group. The control group received routine operative care, whereas the experimental group, in addition to receiving routine operative care, underwent a bedside preoperative pain education and postoperative music intervention program. The study design was based on relevant literature, which holds that pain education can enhance the use of non-pharmacological methods for pain management (Evans, 2002; Pellino et al., 2005; Tracy, 2010).

\subsection{Participants}

Subjects were recruited from four orthopedic wards of a large medical center (2,900 beds) in Taipei, Taiwan, between November 2008 and April 2009. Each ward had a similar setting, patient profile, staff structure, and treatment and pain management protocol. The inclusion criteria were (a) patients scheduled for a primary TKR or THR surgery, (b) patients who were able to communicate in Mandarin or Taiwanese, and (c) patients without hearing problems. Patients with cognitive impairment were excluded. 
We determined the sample size by using G power software (Grant Devilly, Vistoria, Australia). We set $\alpha$ as .05, the effect size for pain as .3 (small), and the power as 0.9 for the 2 groups. The sample size was 30 for each group. We contacted 68 patients awaiting surgery, of whom 63 were eligible for our study. Three patients withdrew from the study. A final 60 patients completed the study ( 30 in the control group and 30 in the experimental group; Figure 1).

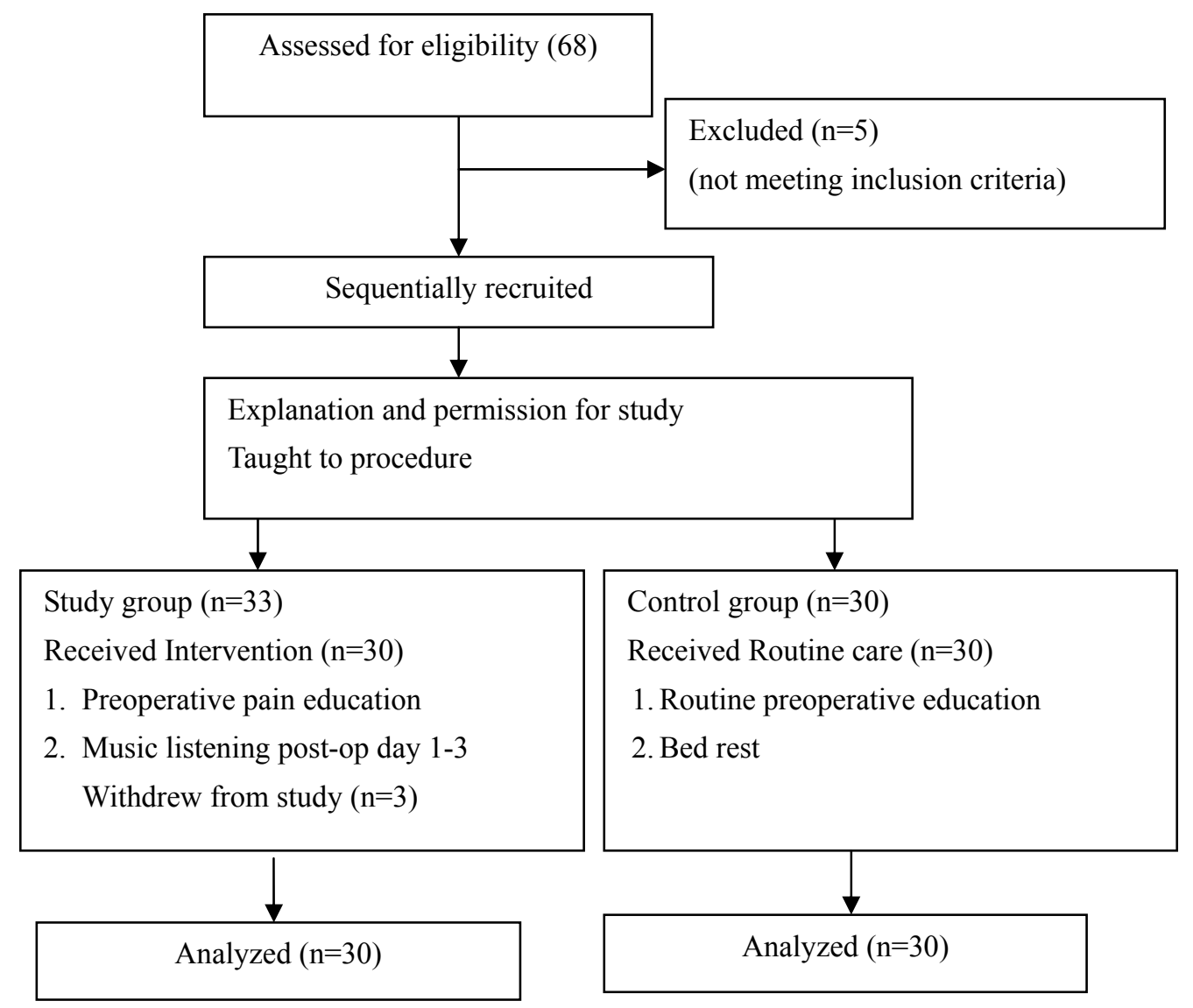

Figure 1. Allocation of subjects

\subsection{Interventions}

\subsubsection{Pain Education Pamphlet}

A pain education pamphlet was designed based on the relevant literature (Cheng \& $\mathrm{Lu}, 2007$ ) and our clinical experiences. Based on the patients' actual beliefs regarding postoperative pain and analgesics use, as well as on an emphasis of the roles of nonpharmacological methods of pain management, the content included knowledge of postoperative pain, the importance of postoperative pain control, pain-relieving methods, the application of patient-controlled analgesia (PCA), the patient's role in pain control, and non-pharmacological strategies such as music (Table 1). We told patients that music listening can help them to relax and relieve discomfort. We also demonstrated the use of the music player and $20 \mathrm{~min}$ each time for listening.

The pamphlet was colorfully illustrated and of a high-quality print that was easy for patients to follow. A draft of the pamphlet was tested for content validity by seven experts (including an orthopedic physician, senior orthopedic nurses, and a nurse supervisor), and the readability was examined by five orthopedic surgery patients with an elementary school education. The pamphlet was finalized according to our experts' opinions. 
Table 1. List of pain education topics and musical selections

\begin{tabular}{|c|c|}
\hline Content of pain education & Types of music \\
\hline 1. What is post-operative pain? & Mandarin and Taiwanese pop songs: \\
\hline 2. The importance of postoperative pain control & 1. Teresa Teng's Small Town Story, You Come \\
\hline 3. How to express how much pain you are suffering: & Again, I only care about you. \\
\hline Pain assessment tool & 2. Jiang Hui's Tonight I want to sing, If the \\
\hline 4. Recognize and practice pain-relieving methods: & drums rang \\
\hline 1) Pain medication: non-steroidal anti-inflammatory & Classical music: \\
\hline drugs and narcotic analgesics & 1.Beethoven's first movement, \\
\hline 2) The application of patient-controlled analgesia & 2.Vivaldi- Four Seasons \\
\hline 3) Non-pharmacological strategies & 3.Schubert's Piano Quintet "Trout" \\
\hline 4) Music listening & Nature sounds: \\
\hline 5. The patient's role in pain control & Morning song, River stream, A walk in \\
\hline 6. Education pamphlet messages: & the forest \\
\hline "We need you to participate in post-operative pain & Buddhist scriptures: \\
\hline control," and & Heart Sutra, Compassion (Anonymous) \\
\hline $\begin{array}{l}\text { "If the pain is not effectively alleviated, please take the } \\
\text { initiative to tell your health care provider." }\end{array}$ & \\
\hline
\end{tabular}

\subsubsection{Music and Music Player}

In this study, we used individualized music intervention. Music was chosen based on patients' ethnic backgrounds. The songs used in this study had 60 to 72 beats per minute and were soft mid- to low-pitch melodies in Mandarin, the native language of Taiwan. The music included pop, classical, and religious music, as well as sounds of nature; Table 1 lists the specific music used. We stored many examples of these four genres into a personal computer, and each patient selected his or her preferred songs. The researchers provided the patient with the same song for all experiences.

We copied each patient's preferred music onto an MP3 player (Topfox Digital MP3 player; Topfox Technology, Taipei, Taiwan) for their use. Each patient listened to music through ear-canal-type earphones, a method of listening found to reduce ambient noise that may influence the curative effect (Joanna Briggs Institute, 2009).

\subsubsection{Intervention Treatment Process}

The education intervention was performed by three trained senior orthopedic nurses. Several group discussions were conducted before the intervention to reach a consensus among the team members in this study.

We provided the experimental group with individual pain education, in addition to routine preoperative education offered by the nursing staff in the unit the day before surgery. Routine preoperative education included pre- and postoperative precautions, rehabilitation exercises, walkers, and home care. Pain management was not particularly stressed. Pain education was performed at patients' bedsides. Based on the pain education pamphlet, we provided detailed instructions to the participants. The lesson lasted $20 \mathrm{~min}$. Afterward, patients were asked to choose a piece of music provided by us and instructed to listen to the music on an MP3 player.

After surgery, we assisted patients to listen to the music every afternoon for $30 \mathrm{~min}$ from the first to the third days. Patients in the control group received routine care: they were offered routine preoperative health education by nursing staff on the afternoon before surgery, and were encouraged to rest in bed for $30 \mathrm{~min}$ before and after evaluating their pain level on Days 1 through 3 after surgery.

\subsubsection{Music Listening Environment}

When the patients wanted to listen to music, a sign was placed outside the patient's door, the ceiling light was turned off, and a curtain was pulled around the twin bed to maintain a quiet atmosphere and prevent the patient's area from being disturbed. The patient was helped into a comfortable position when listening to the music, and a researcher was available to ensure that the patient was not interrupted. 


\subsection{Data Collection}

We approached potential candidates to explain the study and asked them to sign the informed consent form. Participants were enrolled after written consent was obtained. Patients' basic information was collected by reviewing their charts. Both groups filled out a questionnaire on their beliefs about pain management (pretest) before the pain education sessions for the experimental group and before the routine preoperative education for the control group. Patients in the experimental group was asked to evaluate their pain levels 30 min before and after having listened to music, and the control group after having rested in bed for $30 \mathrm{~min}$, on Days 1 through 3 after surgery. On the third postoperative day, both groups were asked to complete a questionnaire on their satisfaction and beliefs about pain management (posttest; Table 2).

Table 2. Procedure and data collection plan (Measurements and times)

\begin{tabular}{lcccc}
\hline & T1 & T2 & T3 & T4 \\
\hline Demographic data & X & & & \\
Belief about pain management & $\mathrm{X}$ & & & X \\
Pain score (VNRS) & & $\mathrm{X}$ & $\mathrm{X}$ & $\mathrm{X}$ \\
Satisfaction with pain management & & & & $\mathrm{X}$ \\
\hline
\end{tabular}

$\mathrm{T} 1=$ before intervention preoperatively; $\mathrm{T} 2$ = day 1 post-op;

$\mathrm{T} 2$ = day 2 post-op; T3 = day 3 post-op.

\subsection{Instruments}

\subsubsection{Numerical Pain Rating Scale}

In this study, we used the verbal numerical rating scale (VNRS; Taiwan version) to measure pain. The VNRS is frequently used to assess pain and the effects of pain management. The patients indicated their degree of pain by using a scale ranging from 0 (no pain) to 10 (the worst pain possible). Such scales have the advantages of being quick and simple and requiring no equipment, and they are easy to understand and do not depend on intact motor skills (Hartrick, Kovan, \& Shapiro, 2003). Strong concurrent validity for a numeric rating scale of 0 to 10 has been documented with a correlation coefficient of 0.92 for a vertical visual analog scale and 0.91 for a verbal descriptor scale (Herr \& Mobily, 1993).

\subsubsection{Music Evaluation Form}

Each patient's subjective evaluation of music was investigated in this study to understand the effects of the patient's subjective experience of music on pain relief. A 4-point scale was adopted, ranging from 0 (no effects) to 4 (positive effects). The music effects evaluation forms were checked for validity by five specialists and were given scores of $1-4$ points according to the fitness of content. The content validity index (CVI) was between 0.8 and 1.0, and the mean score was between 3.2 and 3.8, showing that the scale has strong content validity.

\subsubsection{Patient Beliefs about Pain Management}

This study referred to the scale of beliefs about pain management proposed in a related study (Cheng \& $\mathrm{Lu}$, 2007). We constructed nine statements, including "painkillers cannot completely control pain," "painkillers are highly addictive," "pain is inevitable after surgery," "good patients avoid complaining about pain," and "painkillers may affect wound healing." The questionnaire used a 5-point scale, with 1 indicating a high level of disagreement, and 5 indicating a high level of agreement. A higher score indicated a more negative belief about pain management, whereas a lower score indicated a more positive belief. The content validity index (CVI) was .86, and Cronbach's $\alpha$ was .74, as in Cheng and Lu's study.

\subsubsection{Patient Satisfaction with Pain Management}

The questionnaire was composed of 14 questions, on issues such as whether pain exists after surgery, if pain management should be undertaken, pain levels (on a scale of 0 to 10 points), duration between patients' complaints about pain and response management, if medical personnel demonstrated the importance of pain management, and their satisfaction with pain management. The questionnaire used a 5-point scale ranging from 1 (highly dissatisfied) to 5 (highly satisfied). The correlation coefficient of reliability was .80, and the CVI was .84, as in the study by Lin, Chen, Lin, Tsay, \& Chen (2006). 


\subsection{Ethical Considerations}

The study was approved by the hospital's Institutional Review Board. For participants who met the inclusion criteria, we explained in person the purpose of the study, the study intervention procedure, data collection procedure, and their right to refuse to participate or to opt out at any time. All collected data were anonymously encoded to ensure that participant information remained confidential.

\subsection{Data Analysis}

This study used the Statistical Package for Social Sciences (SPSS, Chicago, IL, USA) software for Windows, version 15.0, to archive and analyze all data. The statistical methods included descriptive statistics, the $t$ test, the paired-sample $t$ test, and repeated-measures analysis of variance (ANOVA). The $p$ value was set to $<.05$, which was accepted as statistically significant.

\section{Results}

\subsection{Demographic Data}

The study comprised 60 patients, of whom 22 were men (36.7\%) and 38 were women (63.3\%). The average age was $64.30 \pm 12.82$ years. In total, 47 patients $(78.3 \%)$ were not employed, and 52 patients $(86.7 \%)$ were married. The most common education level attained was elementary school for 18 patients $(30.0 \%)$. Twenty-three patients $(38.3 \%)$ had received a THR, and $37(61.7 \%)$ had received a TKR. All patients had undergone the respective surgery for the first time, and all postoperative patients needed walking aids. Forty patients (66.7\%) had other health problems in addition to joint diseases; most of them suffered from hypertension (20 patients, $33.3 \%$ ). The demographic characteristics of the 2 groups were compared using a chi-square or $t$ test. No significant statistical differences between the 2 groups were identified, indicating that the data of the 2 groups were homogenous (Table 3).

Table 3. Demographic information of participants $(n=60)$

\begin{tabular}{lccll}
\hline Variables & $\begin{array}{c}\text { Control Group } \\
\mathrm{n}(\%)\end{array}$ & $\begin{array}{l}\text { Study group } \\
\mathrm{n}(\%)\end{array}$ & $\begin{array}{l}\text { Total } \\
\mathrm{n}(\%)\end{array}$ & $\chi^{2} / \mathrm{p}$ \\
\hline Sex & $14(46.7)$ & $8(26.7)$ & $22(36.7)$ & $2.584 / .108$ \\
$\quad$ Male & $16(53.3)$ & $22(73.3)$ & $38(63.3)$ & \\
$\quad$ Female & $63.10(12.80)$ & $65.50(12.94)$ & $64.30 \pm 12.82$ & $.722 / .473$ \\
Mean age M SD & & & & \\
Occupation status & $25(83.3)$ & $22(73.3)$ & $47(78.3)$ & $.884 / .347$ \\
$\quad$ No & $5(16.7)$ & $8(26.7)$ & $13(21.7)$ & \\
$\quad$ Yes & $8(26.7)$ & $7(23.3)$ & $15(25 \%)$ & $.089 / .766$ \\
Religious & $22(73.3)$ & $23(76.7)$ & $45(75 \%)$ & \\
$\quad$ No & & & & \\
$\quad$ Yes & $4(13.3)$ & $4(13.3)$ & $8(13.3)$ & $.000 / 1.00$ \\
Marital status & $26(86.7)$ & $26(86.7)$ & $52(86.7)$ & \\
$\quad$ Single & & & & \\
$\quad$ Married & $4(13.3)$ & $3(10.0)$ & $7(11.7)$ & \\
Education level & $9(30.0)$ & $9(30.0)$ & $18(30.0)$ & $1.487 / .915$ \\
$\quad$ Literacy & $3(10.0)$ & $6(20.0)$ & $9(15.0)$ & \\
Primary school & $7(23.3)$ & $6(20.0)$ & $13(21.7)$ & \\
$\quad$ Junior high school & $7(23.3)$ & $6(20.0)$ & $13(21.7)$ & \\
$\quad$ High school & & & \\
$\quad$ University and above & $12(40.0)$ & $8(26.7)$ & $20(33.3)$ & $1.20 / .412$ \\
Medical history & $18(60.0)$ & $22(73.3)$ & $40(66.7)$ & \\
$\quad$ No & & & & \\
$\quad$ Yes & & &
\end{tabular}

\subsection{Pain Intensity}

The average level of pain on the first postoperative day was $5.83 \pm 2.25$ in the experimental group and $6.47 \pm$ 2.27 in the control group. On Day 2, the average pain level was $4.23 \pm 1.74$ in the experimental group and $4.23 \pm$ 1.41 in the control group. On Day 3, the average pain level was $3.03 \pm 1.85$ in the experimental group and $3.23 \pm$ 
1.57 in the control group. There were no significant differences in pain levels between the 2 groups from the first to the third postoperative day $(p>.05)$.

Statistically significant differences were found in the pain level of patients in the experimental group after undergoing music intervention for Day $1(t=4.826, p=.000)$, Day $2(t=5.517, p=.000)$, and Day $3(t=4.826$, $p=.000)$ following surgery. In the control group, statistically significant differences were found in the pain levels after bed rest on the third postoperative day $(t=2.984, p=.006)$, but not on the first or second day (Table 4).

Table 4. Comparison of pain level between two groups $(n=60)$

\begin{tabular}{|c|c|c|c|}
\hline \multirow{2}{*}{ Variables } & Control group & Study group & \multirow{2}{*}{$\mathrm{t} / \mathrm{p}$ value } \\
\hline & $\mathrm{M} \pm \mathrm{SD}$ & $\mathrm{M} \pm \mathrm{SD}$ & \\
\hline \multicolumn{4}{|l|}{ Post-op day 1} \\
\hline Before Intervention & $4.90 \pm 2.339$ & $4.87 \pm 2.36$ & $-.055 / .956$ \\
\hline After Intervention & $4.43 \pm 1.977$ & $3.47 \pm 2.33$ & $-1.733 / .088$ \\
\hline Paired $\mathrm{t} / \mathrm{p}$ value & $1.249 / .222$ & $4.826 / .000 * * *$ & \\
\hline \multicolumn{4}{|l|}{ Post-op day2 } \\
\hline Before Intervention & $3.12 \pm 2.041$ & $3.37 \pm 1.771$ & $.507 / .614$ \\
\hline After Intervention & $2.66 \pm 1.738$ & $2.50 \pm 1.697$ & $-.347 / .730$ \\
\hline Paired $\mathrm{t} / \mathrm{p}$ value & $1.759 / .089$ & $5.517 / .000 * * *$ & \\
\hline \multicolumn{4}{|l|}{ Post-op day3 } \\
\hline Before Intervention & $2.40 \pm 1.714$ & $2.83 \pm 2.350$ & $.816 / .418$ \\
\hline After Intervention & $1.83 \pm 1.577$ & $2.13 \pm 1.978$ & $.649 / .519$ \\
\hline Paired $\mathrm{t} / \mathrm{p}$ value & $2.984 / .006^{* *}$ & $4.826 / .000 * * *$ & \\
\hline
\end{tabular}

An analysis of the correlation between the participants' basic demographics and their postoperative pain scores on Days 1 through 3 revealed that sex, marital status, occupation status, religion, education level, and medical history did not affect their pain scores $(p>.05)$.

\subsection{Subjective Perceptions of Music Intervention}

Regarding the patient self-evaluation of the effects of listening to music on pain reduction in the experimental group ( 0 to 4 points), the average score on the first day was $1.93 \pm 0.94$, suggesting an acceptable effect; 10 patients $(38.5 \%)$ found the effect satisfying, which was the largest group. The average on the second day was $2.37 \pm 1.13$, and 15 patients $(50 \%)$ found the effect satisfying. The average was $2.63 \pm 0.85$ on the third day, suggesting a satisfying effect. Fourteen patients (46.9\%) considered the effect satisfying, and 4 patients $(13.3 \%)$ found it excellent.

\subsection{Patient Beliefs about Pain Management}

The total score in the pretest was $28.67 \pm 5.17$ in the experimental group and $28.50 \pm 4.58$ in the control group. The total score on the posttest was $27.30 \pm 5.95$ in the experimental group and $26.03 \pm 5.29$ in the control group. Repeated-measures ANOVA was used to analyze the differences between the pretest and posttest in the 2 groups, and the results showed that the difference was significant between the pretest and the posttest $(F=9.789, p$ $=.003)$, but not between the 2 groups $(F=.348, p=.558)$. The most negative item expressed by participants was that "pain is an inevitable postoperative symptom," with a score of $4.60 \pm 0.50$ in the experimental group and $4.77 \pm 0.43$ in the control group. The more positive items included "pain medication may affect the healing of wounds" and "complaining to doctors about pain may distract them from treating diseases" (Table 5).

Table 5. Comparison of pain management beliefs between two groups $(n=60)$

\begin{tabular}{lllllll}
\hline & Pre-test & & Post-test & & Within group & $\begin{array}{l}\text { Between } \\
\text { groups }\end{array}$ \\
\cline { 2 - 7 } & $\mathrm{C}$ & $\mathrm{S}$ & $\mathrm{C}$ & $\mathrm{S}$ & $\mathrm{F} / \mathrm{P}$ value & $\mathrm{F} / \mathrm{P}$ value \\
\hline $\begin{array}{c}\text { 1. Pain medication cannot } \\
\text { completely relieve pain }\end{array}$ & $3.47 \pm 1.196$ & $3.40 \pm 1.102$ & $3.03 \pm 1.217$ & $3.30 \pm 1.291$ & & \\
2. Pain medication is highly & $3.23 \pm 1.194$ & $2.97 \pm 1.189$ & $2.37 \pm 0.964$ & $2.63 \pm 1.129$ & & \\
\hline
\end{tabular}


addictive

3. Good patients avoid

$2.67 \pm 1.184$

complaining about pain

4. Endure pain is easier than enduring the side effects of pain medication

5. Complaining to doctors about pain may distract them from treating diseases
6. Analgesics should be used until the pain gets worse
7. Pain indicates that the condition has become more severe
8. Pain is an inevitable postoperative symptom
9. Pain medication may affect the healing of wounds
Total score

\section{$3.03 \pm 1.033 \quad 3.10 \pm .845 \quad 2.80 \pm 1.270 \quad 2.87 \pm 1.167$}

$2.30 \pm 1.119$

$2.67 \pm 0.922$

$2.20 \pm 0.847$

$2.37 \pm 1.033$

$3.63 \pm 1.245$

$3.53 \pm 1.137$

$3.60 \pm 1.163$

$3.70 \pm 1.317$

$2.93 \pm 1.202$

$3.00 \pm 1.017$

$2.40 \pm 0.855$

$2.77 \pm 1.104$

$4.57 \pm 0.504$

$4.33 \pm 0.711$

$4.77 \pm 0.430$

$4.60 \pm 0.498$

$2.67 \pm 0.844$

$2.90 \pm 0.960$

$2.27 \pm 0.868$

$2.37 \pm 0.809$

$28.50 \pm 4.576$

$28.67 \pm 5.168$
$27.30 \pm 5.948$

$\begin{array}{ll}9.789 / & .348 / \\ .003 * & .558\end{array}$

Note. $\mathrm{S}=$ Study group, $\mathrm{C}=$ Control group.

$* \mathrm{p}<.05$.

\subsection{Patient Satisfaction with Pain Management}

Regarding satisfaction with overall pain relief, the scores were $4.52 \pm 0.78$ in the control group and $4.41 \pm 0.63$ in the experimental group. The average score of total satisfaction with pain management was $4.38 \pm 0.77$ in the control group and $4.41 \pm 0.58$ in the experimental group, indicating that both groups had high satisfaction levels with pain management by the nursing staff, and no significant difference was found between the groups $(t=.193, p$ $=.847$ ). The average duration from when patients complained to nursing staff about pain until the pain was treated was $9.46 \pm 22.80 \mathrm{~min}$ in the experimental group and $8.26 \pm 4.24 \mathrm{~min}$ in the control group $(t=.269, p=.789)$, with a significant difference between the groups.

\section{Discussion}

In this study, the postoperative pain level in the experimental group decreased significantly after they listened to music. However, there was no significant difference between the 2 groups on the average pain level for the 3 days following surgery. A possible reason might be that the effects on pain of listening to music were not continuous, but occurred only while listening or for a short period immediately afterward. Another possible reason for the lack of significant differences between the groups is that the bed rest for the control group is also a form of intervention.

The relevant literature presented inconsistent results regarding the effects of music listening on pain reduction in patients who had undergone surgery. For example, Nilsson (2008) reviewed 42 randomized controlled trials of the effects of music intervention in perioperative settings. The results showed that music intervention had positive effects for reducing patients' pain in approximately half of the reviewed studies. Our findings differ from some previous studies (Lin et al., 2011; Özer, Özlü, Arslan, \& Günes, 2013; Sendelbach et al., 2006). Sendelbach et al. (2006) compared the effects of music listening versus a quiet, uninterrupted rest period on pain intensity, physiological parameters, and opioid consumption after cardiac surgery. Fifty patients listened to music for $20 \mathrm{~min}$ (intervention), whereas 36 patients had $20 \mathrm{~min}$ of bed rest (control). The results showed a significant reduction in pain, but no difference was observed in systolic blood pressure, diastolic blood pressure, heart rate, and opioid usage in the 2 groups. Lin et al. (2011) examined the effects of music on patient pain after spinal surgery. The VAS score of pain in the experimental group was found to be significantly lower than in the control group, whereas no significant effect was found on stress-related physical indicators (urine cortisol, epinephrine, and norepinephrine).Also, Özer et al. (2013) investigated the effect of listening to personal choice of music on self-report of pain intensity and the physiologic parameters in 44 patients who have undergone open 
heart surgery, whereas 43 patients had a rest in their beds. The results showed that the music group had a statistically significant increase in oxygen saturation and a lower pain score than in the control group.

However, the results of this study are consistent with the findings of other studies, which showed that the music group's decrease in pain was not significantly different from that of the compared rest group (Allred, Byers, \& Sole, 2010; Bechtold et al., 2009). Allred et al. (2010) compared the effects of listening to music or having a quiet rest period immediately before and immediately after the first ambulation on Postoperative Day 1 on reducing pain and affecting the mean arterial pressure, heart rate, respiratory rate, and oxygen saturation in 56 patients who had undergone a total knee arthroplasty. Statistical findings between groups indicated that the decrease in pain for the music group was not significantly different from the decrease in pain for the compared rest group at any measurement point. However, statistical findings within groups indicated that the sample had a statistically significant decrease in pain over time. This research provided evidence supporting the use of music and/or a quiet rest period for reducing pain and anxiety. Bechtold et al. (2009) conducted a meta-analysis to analyze the effect of music on patients who had undergone a colonoscopy. Eight studies $(N=712)$ were included, and the results showed that patients' overall experience scores had improved significantly because of music intervention. No significant differences were noted for patients' pain scores.

In the experimental group in this study, most patients expressed a positive attitude toward the effects of music listening. All participants accepted music listening on all 3 days, with none opting out, indicating that music listening is acceptable for this type of surgical patient, and that patients were able to perform music listening independently as required. Most subjects in the experimental group listened to music on their own once or twice a day. Twenty-one patients $(80.76 \%)$ listened to music once or twice of their own accord on the first day, 20 $(66.7 \%)$ on the second, and $13(43.33 \%)$ on the third. Ten patients $(33.33 \%)$ listened to music of their own accord three to five times on the third postoperative day, and seven patients $(23.33 \%)$ listened more than five times. This might be because patients experienced greater benefits from listening to music, and thus, increased the listening frequency.

In this study, patients were provided with pain education in the hope that they would have more positive beliefs about pain management after pain education. The result showed significant differences in beliefs about pain management between the pretest (preoperative) and posttest (postoperative Day 3), but no significant difference was found between the 2 groups. The control group also demonstrated positive beliefs about pain management in the posttest. Although pain education was not provided to the control group, patients had probably already received relevant pain management and instruction from medical personnel. This result differs from those reported by Wong et al. (2010), who examined the effect of an educational intervention on pain beliefs. They found a statistical difference in the pain barrier score between patients in the education group and patients in the control group in a sample of patients who had undergone orthopedic surgery for limb fractures. This might be due to the difference in educational intervention content between the study by Wong et al. and our study. In their study, the educational intervention content included material on the benefits of good pain management and breathing relaxation exercises, and encouraged participants to have a positive attitude when facing pain. However, in our study, we provided patients with more information about postoperative pain, PCA, and music listening, as non-pharmacological strategies. Our findings also differed from those by Cheng and Lu (2007), who stated that the experimental group showed a more positive attitude toward pain management compared to the control group. This might have been because their study provided participants with reinforcement pain education on the day after surgery. Therefore, we recommend a different pain educational program, which included postoperative reinforcement education in addition to preoperative education. In addition, future studies could adopt a design that includes different pain educational content, to compare the effects of educational intervention on beliefs about pain management.

Among patient beliefs about pain management, the most negative item was "pain is an inevitable postoperative symptom." This is similar to the findings obtained by Lin, Lin, \& Yao (2001). The pain education we provided could not change this culturally deeply rooted Taiwanese concept. Patients still experienced pain on the third day, but they did not request further pain management. This reinforces our findings on patient beliefs about postoperative pain management, and was consistent with patient expectations.

No significant difference was found in the satisfaction levels with pain management between the 2 groups. This result is consistent with those by Cheng and Lu (2007) and Simcock et al. (2008), indicating that music did not improve patient satisfaction with pain management. However, McCaffrey and Locsin (2006) found a higher level of satisfaction with pain management in the music listening group. Based on a design by Lin et al. (2011), we provided patients with music listening for one 30-min session daily. However, McCaffrey and Locsin provided patients with more music intervention (four times a day for $1 \mathrm{hr}$ each time). Thus, the differing results 
between our study and the McCaffrey and Locsin study might be due to the differences in music listening time between the two interventions. Although patients were encouraged to listen to music on their own whenever they felt the need to, most patients listened to music only once or twice on their own. Whether increasing the frequency and duration of music listening would improve patients' satisfaction levels requires further examination. Another possible reason for the lack of significant differences between the 2 groups is that, because patient satisfaction with pain management in both groups was $>4$ points, space was limited for the satisfaction score to improve.

\section{Conclusion}

The results of this study showed that, although the pain levels of patients in the experimental group decreased significantly after listening to music, no significant difference was found in the average pain level between the 2 groups. Most patients in the experimental group expressed a positive attitude toward the effects of music listening. Beliefs about pain management were more positive after surgery than before the pain education, but no significant difference was found between the 2 groups. Patients from both groups reported high satisfaction levels with pain management, but no significant difference was found between the 2 groups.

\section{Study Limitation and Recommendation}

This study has three limitations. First, the three trained nurses who participated in the study may have implemented the interventions differently, which could have affected the results. Second, because opioid consumption may be a confounding variable, its measurement was not included in this study. Third, that the control group was asked to take bed rest for $30 \mathrm{~min}$ before evaluating their pain may also be considered a form of intervention.

In clinical nursing practice, managing postoperative pain in patients who have undergone total joint replacement surgery is important. In addition to pharmacological treatment, non-pharmacological strategies are indispensable. Although the results of this study indicate that no effects on pain relief and positive belief about pain management were observed in patients who received pain education and listened to music compared with patients receiving routine care, most patients' subjective expression listening to music on pain relief was satisfied. We believe that nurses can provide music as a complementary intervention in this patient population to improve pain management satisfaction.

In this study, the combined effects of patient education and music listening on reducing pain were not confirmed. In future studies, an additional group of patients who are not provided any form of intervention would facilitate comparisons of the significant effect of music listening and education. An improved study design could include a larger sample to improve the generalizability of the results. Furthermore, physical indicators such as vital signs and opioid consumption could be included to expand the experiment.

\section{Acknowledgements}

This study was financially sponsored by the Taipei Medical University (Grant No TMU97-AE1-B02). We hereby, thank all the patients who participated in this research for their cooperation.

\section{References}

Akyol, Ö., Karayurt, Ö., \& Salmond, S. (2009). Experiences of pain and satisfaction with pain management in patients undergoing total knee replacement. Orthopaedic Nursing, 28(2), 79-85. https://doi.org/10.1097/NOR.0b013e3181945f62

Allred K.D., Byers, J., \& Sole, M.L. (2010). The effect of music on postoperative pain and anxiety. Pain Management Nursing, 11(1), 15-25. https://doi.org/10.1016/j.pmn.2008.12.002

Bechtold, M.L., Puli, S.R., Othman, M.O., Christopher, R.B., Marshall, J.B., \& Roy, P. (2009). Effect of music on patients undergoing colonscopy: A meta-analysis of randomized controlled trials. Digestive Diseases \& Sciences, 54, 19-24. https://doi.org/10.1007/s10620-008-0312-0

Brown, D. (2004). A literature review exploring how healthcare professionals contribute to the assessment and control of postoperative pain in old people. Journal of Clinical Nursing, 13(6B), 74-90. https://doi.org/10.1111/j.1365-2702.2004.01047.x

Brunges, M.J., \& Avigne, G. (2003). Music therapy for reducing surgical anxiety. AORN Journal 78, 816-818. https://doi.org/10.1016/S0001-2092(06)60641-8

Busch, C.A., Shore, B.J., Bhandari, R., Ganapathy, S., MacDonald, S.J., \& Bourne, R.B., et al. (2006). Efficacy of periarticular multimodal drug injection in total knee arthroplasty. The Journal of Bone and Joint Surgery, 
88A(5), 959-963. https://doi.org/10.2106/00004623-200605000-00005

Buyukyılmaz, F., \& Ast1, T. (2013). The effect of relaxation techniques and back massage on pain and anxiety in Turkish total hip or knee arthroplasty patients. Pain Management Nursing, 14(3), 143-154. https://doi.org/10.1016/j.pmn.2010.11.001

Buyukyılmaz, F.E., \& Astı, T. (2010). Postoperative pain characteristics in Turkish orthopaedic patients. Pain Management Nursing, 11(2), 76-84. https://doi.org/10.1016/j.pmn.2009.01.003

Cepeda, M.S., Carr, D.B., Lau, J., \& Alvarez, H. (2006). Music for pain relief. Cochrane Database of Systematic Review, 2, CD4843, 1-45. https://doi.org/10.1002/14651858.cd004843.pub2

Chen, S.R., Chen, C.S., \& Lin, P.C. (2014). The effect of educational intervention on the pain and rehabilitation performance of patients who undergo a total knee replacement. Journal of Clinical Nursing, 23, 279-287. https://doi.org/10.1111/jocn.12466

Cheng, Y.H., \& Lu, M.S. (2007). The effects of preoperative pain education on improving patients' pain experience after spinal surgery. Evidence Based Nursing, 3(2), 107-118.

Engwall, M., \& Duppils, G.S. (2009). Music as a nursing intervention for postoperative pain: A systematic review. Journal of PeriAnesthesia Nursing, 24(6), 370-383. https://doi.org/10.1016/j.jopan.2009.10.013

Evans, D. (2002). The effectiveness of music as an intervention for hospital patients: A systematic review. Journal of Advanced Nursing, 37(1), 8-18. https://doi.org/10.1046/j.1365-2648.2002.02052.x

Gatlin, C.G. (2007). When medication is not enough: Nonpharmacologic management of pain. Clinical Journal of Oncology Nursing, 11(5), 699-704. https://doi.org/10.1188/07.CJON.699-704

Giannoudis, P.V., Dinopoulos, H., Chalidis, B., \& Hall, G.M. (2006). Surgical stress response. International Journal of the Care of the Injured, 37S, S3-S9. https://doi.org/10.1016/S0020-1383(07)70005-0

Hartrick, C.T., Kovan, J.P., \& Shapiro, S. (2003).The numeric rating scale for clinical pain measurement: A Ratio Measure?. Pain Practice, 3(4), 310-316. https://doi.org/10.1111/j.1530-7085.2003.03034.x

Herr, K., \& Mobily, P. (1993). Comparison of selected pain assessment tools for use with the elderly. Applied Nursing Research, 6, 39-46. https://doi.org/10.1016/S0897-1897(05)80041-2

Hill, N., \& Davis, P. (2000). Nursing care of total joint replacement. Journal of Orthopaedic Nursing, 4, 41-45. https://doi.org/10.1054/joon.2000.0060

Joanna Briggs Institute. (2009). Clinical update 130. Music as an intervention in hospitals. Australian Nursing Journal, 17, 29-31.

Joelsson, M., Olsson, L.E., \& Jakobsson, E. (2010). Experience of pain and pain relief following hip replacement $\begin{array}{lllll}\text { surgery. Journal of } & \text { Clinical }\end{array}$ https://doi.org/10.1111/j.1365-2702.2010.03215.x

Lin, L.C., Chen, M.L., Lin, C.C., Tsay, P.K., \& Chen, H.C. (2006). Quality evaluation of postoperative pain management. Chang Gung Nursing, 17(1), 1-9.

Lin, P.C. (2012). An evaluation of the effectiveness of relaxation therapy for patients receiving joint replacement surgery. Journal of Clinical Nursing, 21, 601-608. https://doi.org/10.1111/j.1365-2702.2010.03406.x

Lin, P.C., Fujita, K., Chang, S.Y., \& Liu Y.Y. (2016). Patient life experience and activity of daily living before and after total knee arthroplasty. Open Journal of Nursing, 6, 658-671. https://doi.org/10.4236/ojn.2016.69069

Lin, P.C., Lin, C.C., \& Yao, E. (2001). Pain control for post-spine surgery patients: A survey of the effectiveness of Demerol IV drip Q4H prn. The Journal of Nursing, 48(2), 49-57.

Lin, P.C., Lin, M.L., Huang, L.C., Hsu, H.C., \& Lin, C.H. (2011). Music therapy for patients receiving spine surgery. Journal of Clinical Nursing, 20, 960-968. https://doi.org/10.1111/j.1365-2702.2010.03452.x

Lukas, L.K. (2004). Orthopedic outpatients' perception of perioperative music listening as therapy. Journal of Theory Construction \& Testing, 8(1), 7-12.

McCaffrey, R., \& Locsin, R. (2006). The effect of music on pain and acute confusion in older adults undergoing hip and knee surgery. Holistic Nursing Practice, 20(5), 218-224. https://doi.org/10.1097/00004650-200609000-00002 
Nilsson, U. (2008). The anxiety- and pain-reducing effects of music interventions: a systemic review. AORN Journal, 87(4), 780-807. https://doi.org/10.1016/j.aorn.2007.09.013

Özer, N., Özlü, Z.K., Arslan, S., \& Günes, N. (2013). Effect of music on postoperative pain and physiologic parameters of patients after open heart surgery. Pain Management Nursing, 14(1), 20-28. https://doi.org/10.1016/j.pmn.2010.05.002

Parker, R.J. (2011). Evidence-based practice caring for a patient undergoing total knee arthroplasty. Orthopaedic Nursing, 30, 4-8. https://doi.org/10.1097/NOR.0b013e3182057451

Pasero, C., \& McCaffery, M. (2007). Orthopedic postoperative pain management. Journal of PeriAnesthesia Nursing, 22(3), 160-174. https://doi.org/10.1016/j.jopan.2007.02.004

Pellino, T.A., Gordon, D.B., Engelke, Z.K., Busse, K.L., Collins, M.A., Silver, C.E., \& Norcross, N.J. (2005). Use of nonpharmacologic interventions for pain and anxiety after total hip and total knee arthroplasty. Orthopaedic Nursing, 24(3), 182-192. https://doi.org/10.1097/00006416-200505000-00005

Sagrillo, D.P., \& Mooney, K.M. (2000). Current trends in postoperative pain management. Plastic Surgical Nursing, 20, 230-233. https://doi.org/10.1097/00006527-200020040-00009

Sendelbach, S.E., Halm, M.A., Doran, K.A., Miller, E.H., \& Gaillard, P. (2006). Effects of music therapy on physiological and psychological outcomes for patients undergoing cardiac surgery. Journal of Cardiovascular Nursing, 21(3), 194-200. https://doi.org/10.1097/00005082-200605000-00007

Simcock, X.C., Yoon, R.S., Chalmers, P., Geller, J.A., Kiernan, H.A., \& Macaulay, W. (2008). Intraoperative music reduces perceived pain after total knee arthroplasty: A blinded, prospective, randomized, placebo-controlled clinical trial. The Journal Knee Surgery, 21(4), 275-278. https://doi.org/10.1055/s-0030-1247831

Stomberg, M.W., \& Oman, U.B. (2006). Patients undergoing total hip arthroplasty: A perioperative pain experience. Journal of Clinical Nursing, 15(4), 451-458. https://doi.org/10.1111/j.1365-2702.2006.01363.x

Tracy, S. (2010). Piloting tailored teaching on nonpharmacologic enhancements for postoperative pain management in older adults. Pain Management Nursing, 11(3), 148-158. https://doi.org/10.1016/j.pmn.2009.06.002

Tracy, S., Dufault, M., Kogut, S., Martin, V., Rossi, S., \& Willey-Temkin, C. (2006). Translating best practices in nondrug postoperative pain management. Nursing Research, 55(2S), S57-S67. https://doi.org/10.1097/00006199-200603001-00010

Vallerand, A.H., Foulabakhsh, J., \& Templin, T. (2005). Patients' choices for the self-treatment of pain. Applied Nursing Research, 18(2), 90-96. https://doi.org/10.1016/j.apnr.2004.07.003

Wong, E.M., Chan, S., \& Chair, S.Y. (2010). The effect of educational intervention on pain beliefs and postoperative pain relief among Chinese patients with fractured limbs. Journal of Clinical Nursing, 19, 2652-2655. https://doi.org/10.1111/j.1365-2702.2010.03260.x

\section{Copyrights}

Copyright for this article is retained by the author(s), with first publication rights granted to the journal.

This is an open-access article distributed under the terms and conditions of the Creative Commons Attribution license (http://creativecommons.org/licenses/by/4.0/). 